\title{
Web-Based Expert System to Detect Stress on College Students
}

\author{
Grensya Bella Vega Persulessy ${ }^{1}$, Nova S. Pratama ${ }^{2}$, \\ Novianti Setiawan ${ }^{3}$, and Nina Sevani ${ }^{4}$ \\ ${ }^{1,2,3,4}$ Department of Informatics Engineering, Faculty of Engineering and Computer Science, \\ Universitas Kristen Krida Wacana \\ Jln. Tanjung Duren Raya No.4, Jakarta Barat 11470, Indonesia \\ 'grensya.2014tin006@civitas.ukrida.ac.id; 2nova.2014tin032@civitas.ukrida.ac.id;

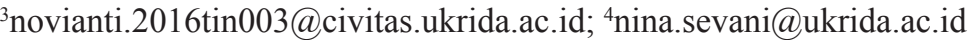

Received: $12^{\text {th }}$ September 2018/ Revised: $13^{\text {th }}$ November 2018/ Accepted: $16^{\text {th }}$ November 2018

How to Cite: Persulessy, G. B. V., Pratama, N. S., Setiawan, N., \& Sevani, N. (2019). Web-Based Expert System to Detect Stress on College Students. ComTech: Computer, Mathematics and Engineering Applications, 10(1), 9-14. https://doi.org/10.21512/comtech.v10i1.4987

\begin{abstract}
This research aimed to make the application to detect stress for the college students. By early detecting stress on college students, it could help them to cope with their stress and avoid the negative impact of the stress. The Holmes-Rahe Readjustment Rating Scale was used to detect stress based on student's life events. Each event had its score. There were 31 questions provided by the system. The final score would conclude the stress categories. Using the Forward Chaining Inference Engine, the system would collect the fact of the student's life and give the result by accumulating scores on questions posed to the users from every question. The system also provided the reminder feature that led to continuous monitoring of stress condition in the students. About 65 respondents who were selected using random sampling were asked to fill out questionnaires regarding this system after they tried the application. With the continuous monitoring, the researchers find that this system gives a result that all users have decreased their score of stress levels. Moreover, the correspondents rate that the design of the application is good enough, and the system is interesting and useful for helping students to provide a solution for stress.
\end{abstract}

Keywords: web-based expert system, stress detection, college students

\section{INTRODUCTION}

Activity as a student is part of a routine that has its psychological pressure leading to stress. Pressure caused by the deadline of various tasks and activities may lead to a condition of discomfort. This discomfort condition affecting the life events can be concluded as stress (Oguntimilehin, Abiola, \& Adeyemo, 2015). Academic stress is the usual case experienced by students, whether studying at school or college. This is due to many academic demands. Some researchers have defined that stress can lead to a decrease in academic capability (Gaol, 2016).

Moreover, stress can make a person's lifestyle become unhealthy and trigger a variety of diseases such as stroke, hypertension, dysfunction of body systems, and sudden death in some cases (Oguntimilehin, Abiola, \& Adeyemo, 2015). Stress can also damage social relationships in the family and the social environment. It may even lead to a decrease in the productivity level of a person (Billings, Cook, Hendrickson, \& Dove, 2008). A large number of negative impacts caused by stress can be overcome by getting a proper diagnosis of his/her psychological condition. It is the right solution to cope with the stress experienced (Chakraborty et al., 2013).

Sometimes college students do not realize that they have stress and neglect its negative effect. This can make them avoid to meet the psychologist. To get a proper diagnosis of a psychological condition, they should consult with the psychologist (Silitonga \& Budiharto, 2015). Besides the lack of student awareness about their stress condition, the cost becomes another reason for the student to meet the psychologist. Whereas college students need helps to overcome their stress problem before it leads to an unhealthy condition.

By looking at the conditions in which the students are very likely to experience stress, it is necessary to have a proper way to do early detection of stress for the student. This early detection also can help the student to cope with their stress before its negative impact occurs. The existence of computer technology can be implemented in the world of health in the field of psychological health stress diagnosis (Oguntimilehin, Abiola, \& Adeyemo, 2015). To make a diagnosis of stress like a psychologist, a website-based expert system can be created. It can provide ease of use to all users (Sevani \& Silvia, 2015). The use of the website also can provide convenience for the users to get a solution based on the detection obtained (Billings et al., 2008). Many psychological methods can be used to diagnose stress in a person. In this case, one of the methods that can be used to detect stress in students is Holmes-Rahe Readjustment 


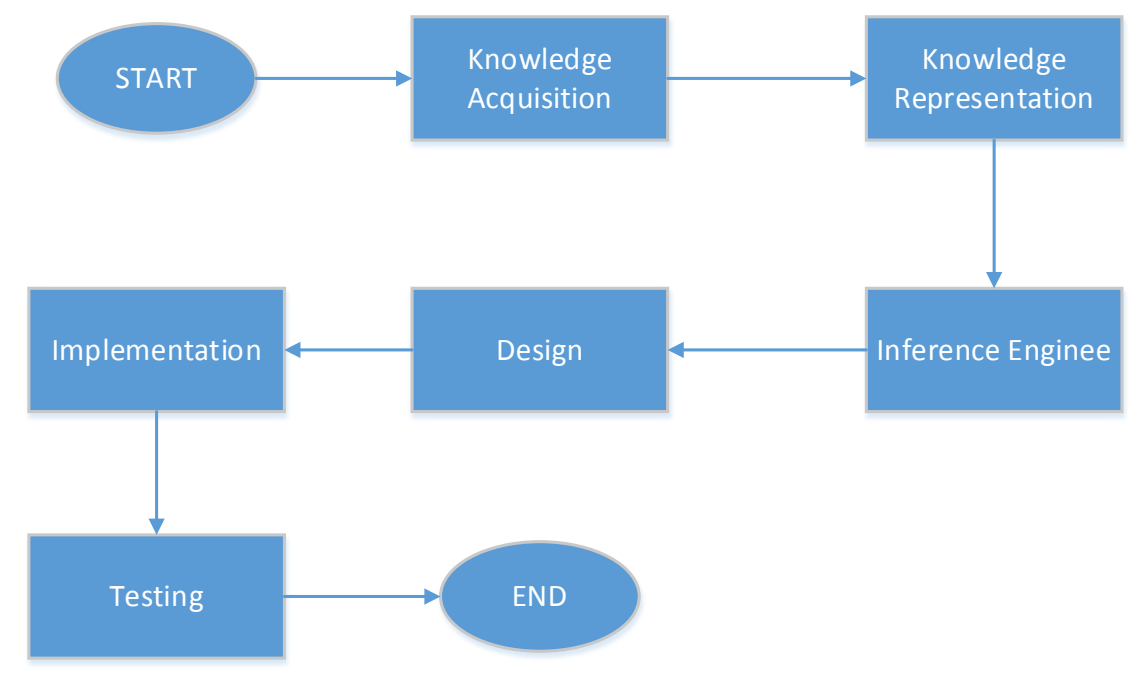

Figure 1 Research Stage

Rating Scale. This method provides a scale of values to the questions given to the user with a certain weight value on each question that will be answered. This method gives a diagnostic result based on the total score obtained (Felsten, 2004).

Some previous researches have been done. It is related to the use of the expert system of psychological health stress. Haidar, de Vries, Karavetian, and El-Rassi (2018) revealed that status as a student could influence their stress levels. Meanwhile, Oguntimilehin, Abiola, and Adeyemo (2015) implemented the characteristics or conditions when a person had stress symptoms. This research generated a computer-based diagnosis system to get a stress diagnosis. Felsten (2004) defined a stress scale for the students called as Social Readjustment Rating Scale. This scale is used as a standard scale in this research. Moreover, Allexandre et al. (2016) showed that the website could be an effective media for the user to detect stress. The website could detect the stress level every time in every place without meeting psychologist.

Based on the situation, there is a benefit of making the application to detect stress for the student. It can perform early detection of stress independently and give the right solution. Thus, the students can get better in managing their mental health to overcome the stress before it becomes a trigger to another disease.

\section{METHODS}

The stages and the design of the research conducted can be shown in Figure 1. The first stage in this research is knowledge acquisition. This stage is done by studying some previous research about stress detection from the journal, interview with college students about their stress experience, and discussion with the expert in this field. The purpose of this stages is to obtain valid information and insight about the domain of the research. The experts who are involved are the psychologist as a source of knowledge to detect stress.

The second stage in this research is knowledge representation. This research uses rule method as the knowledge representation. In the rule-based representation, the knowledge will be written in the form of IF (condition)
THEN (conclusion).

The third stage is the inference engine. It is the approach step to get the conclusion or detection result. The researchers use the Forward Chaining Inference method. It is an expert system by making an inference of reasoning from a problem to get the solution. This method is done by accepting the input condition or fact and giving the response of conclusion as output to the users' psychologist (Silitonga \& Budiharto, 2015).

The fourth stage is the design process. This application is designed to detect the stress level in college students by giving the questions to users. The questions are from the Holmes-Rahe Readjustment Rating Scale. Each question has their score. The question with the score is describeb in Figure 2. The results determine the level of stress in each user. For more details of this system work process, a flowchart detection system application is shown in Figure 3. This system is designed for two type of users. The first one is an admin for this application. The second one is the users who use this application. Those users have a different role. The difference between users permission is described in use case in Figure 4. Figure 5 shows the hierarchical menu in the system. Then, the user interface design is on Figure 6 and Figure 7.

The fifth stage is implementation. All the application concepts designed at the previous stages will be implemented using PHP programming language and MySQL as the database. The result of this implementation stage is a website to detect stress for college students. The sixth stage in this research is testing. This stage is done after the application is completed and ready to use by the users. The purpose of this stage is to find out the errors in the system. Testing stage is done by using two techniques. Those are the white box and black box testings. Black box testing is done to determine whether all the functions in the system has been running in accordance with functional requirements and the desired process by the users. White box testing shows how the system works in detail according to the system specifications (Subawa, Wirawan, \& Sunarya, 2015).

To determine the success rate of this system, it can be seen from the total score obtained by the users in the first stress detection test. Then, it will be compared to the result of the next stress detection test. Using random sampling, the participants for Black box testing are selected. There are 65 
active students at Krida Wacana Christian University who fill in the questionnaire about the system. The questionnaire is made by using Google Form. Then, it is constructed by the researchers based on the goal of this application.

\section{RESULTS AND DISCUSSIONS}

The Holmes-Rahe Readjustment Rating Scale will diagnose stress level based on the life event. Every life event has a different score as shown in Figure 2.

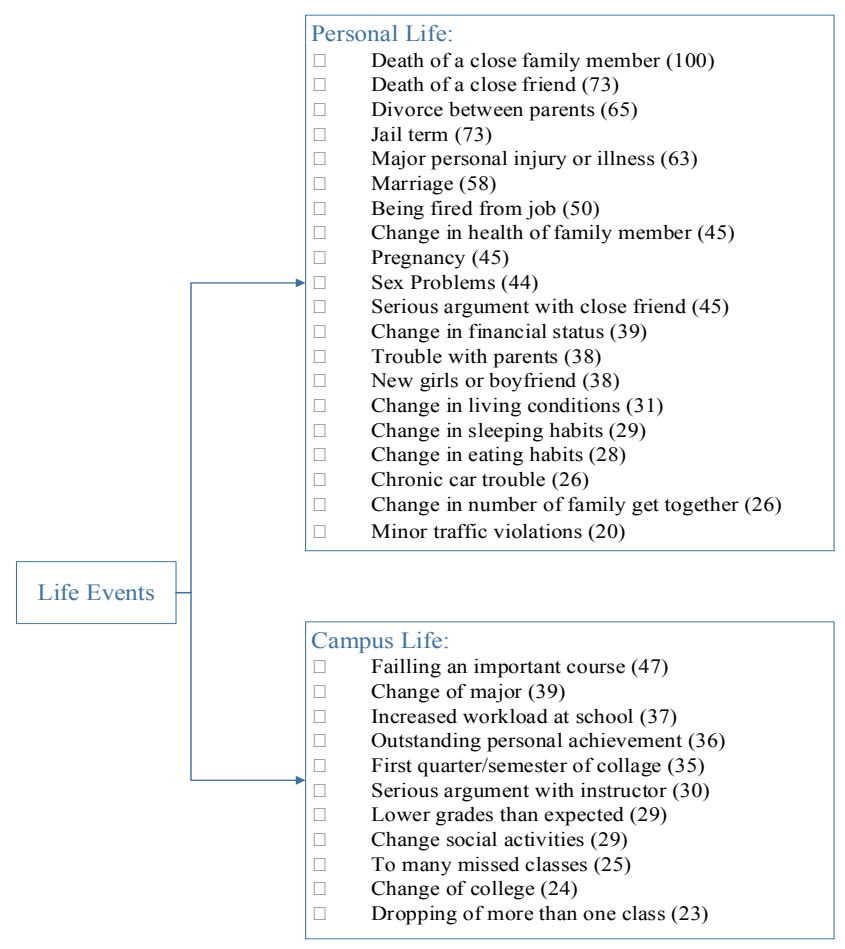

Figure 2 Life Events Score

There are 31 questions about life events that are classified into two categories. The first class is personal life. Then, the second class is campus life. The question is provided by the system and has to be answered by the users. Every answer has its score. The total score will be calculated and displayed at the end of the detection process. This score is the representation from the Holmes and Rahe Social Readjustment Rating Scale. Classification of the total score is based on this syntax as follows:

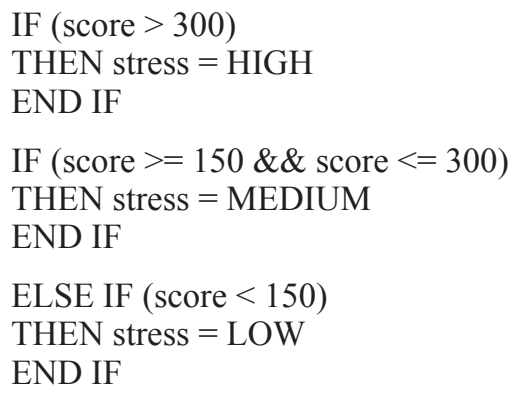

The classification result from this application is conducted by the total score from the users' answers. Every score from the answer will be calculated. After getting the detection result, the system will give an output. The output is the general solutions to overcome the stress. The solution is given based on the detection results which are high, medium, and low. If the total score is more than 300, the application will give a result that the users have high stress. If the total score is more than 150 and lower than 300 the users have medium stress. Then, if the total score is lower than 150 , the users have low stress.

The obtained knowledge from the experts will be stored in a knowledge-based as rules using a database system. The knowledge-based contains questions along with the score. When the users answer the question, their answer will be compared with the knowledge in the knowledgebased and the score will be calculated. For example, the system will ask the user "Do you have an occupation ?". The answer from the users will be compared with the rules in the knowledge-based. If the user answers "Yes", they will get the score of 0 . If their answer is "No", they will get a score of 50 .

Stress detection process in this system is described in Figure 3. It explains the flow process in this stress detector system. This system begins with checking the process to verify users' account in the system. Only the users that already have an account can log in to the system. If the users do not have an account, they have to register first.

After registering and entering the system successfully, the users can use the stress detection menu in which they have to answer all the question to get the result and the solution. For the users that have stress, they can activate the reminder system to help them to do continuous measurement about their stress. The continuous measurement also can help the user to monitor their progress to cope with their stress. This system also provides a history menu. It lists the time, stress score, and test result about users' test activity that has been done in the system.

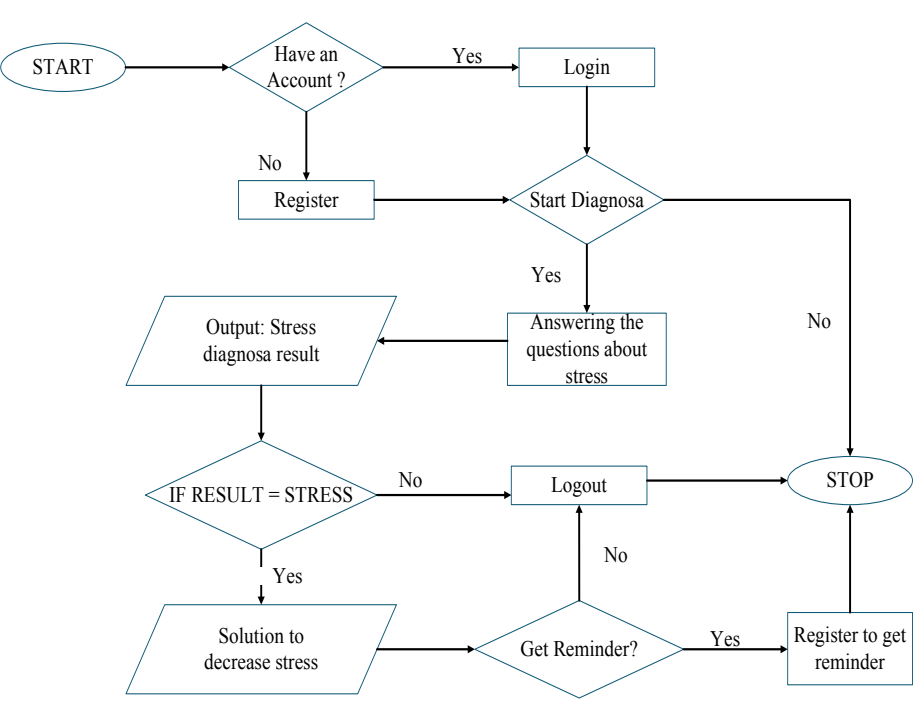

Figure 3 Flowchart of Detection System

This system has two types of user. Those are the user and admin. The different role of both users is illustrated in the use case in Figure 4 with the description in Tabel 1.

In this system, the admin has a right to login or register, add or edit fact and questions for diagnosis, add or edit solutions, and give a reminder to do a test for the users based on their request. The users can use the diagnosis menu and get the result, view and edit user profile, view users' diagnosis result, view users' diagnosis history, and get a reminder. 


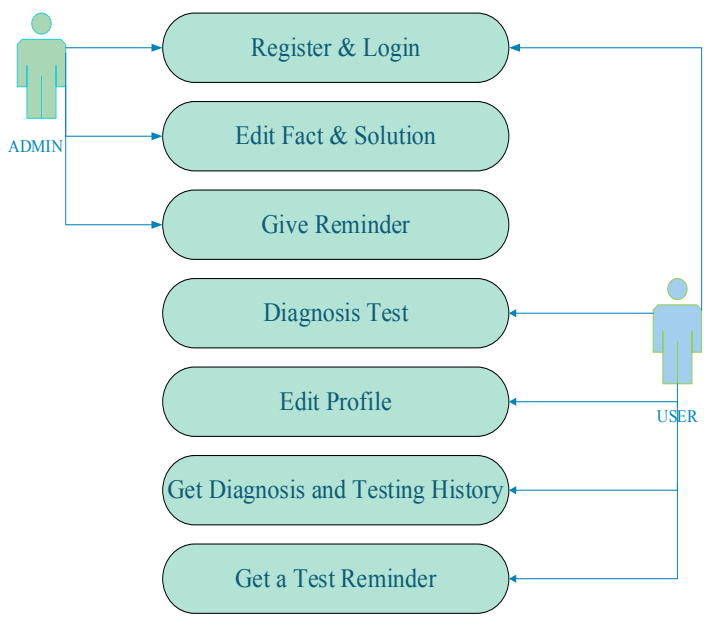

Figure 4 Use Case

Table 1 Use Case: System to Detect Stress on College Students

Actor: Admin and user

Pre-Condition: Admin and user use this application

Post-Condition: Admin and user can use this system

\begin{tabular}{lll}
\hline $\begin{array}{l}\text { User } \\
\begin{array}{l}\text { 1. The user can log } \\
\text { in after registering }\end{array}\end{array}$ & $\begin{array}{l}\text { Admin } \\
\text { 1. Admin can log } \\
\text { in after registering }\end{array}$ & $\begin{array}{l}\text { System } \\
\text { 1. The system will } \\
\text { do data validation } \\
\text { in the database }\end{array}$ \\
$\begin{array}{l}\text { 2. Users log in to } \\
\text { do the test }\end{array}$ & $\begin{array}{l}\text { 2. Admin can } \\
\text { edit the fact and } \\
\text { solution data in the } \\
\text { system }\end{array}$ & $\begin{array}{l}\text { 2. The system } \\
\text { will show an error } \\
\text { message if the } \\
\text { validation process } \\
\text { fails }\end{array}$ \\
$\begin{array}{l}\text { 3. Users can request } \\
\text { the system to give } \\
\text { the test reminder }\end{array}$ & $\begin{array}{l}\text { 3. Admin can send } \\
\text { reminder based on } \\
\text { the user request }\end{array}$ & $\begin{array}{l}\text { 3. The system will } \\
\text { bring the user or } \\
\text { admin on their } \\
\text { selection page }\end{array}$ \\
$\begin{array}{l}\text { 4. Users can view } \\
\text { their test history }\end{array}$ & & \\
\hline
\end{tabular}

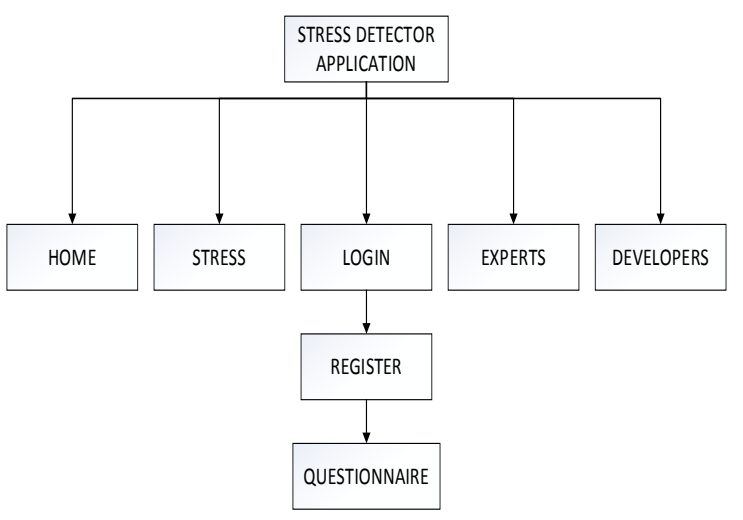

Figure 5 Hierarchical Menu in the System
This system has several menus like home, stress, login with a submenu to register, questionnaires, experts, and developer menu. The hierarchy of the menu is shown in Figure 5. This system application shows the hierarchical menu for the users. The first hierarchy will show the homepage menu for the users without login to this system. The second hierarchy menu is registration and questionnaire menu. There are menus shown for the users after the login to the system.

The example of the interface of some menu of the system is shown in Figure 6 and 7. Figure 6 shows the interface of the questionnaire menu. This menu can be accessed if the users register to the system and log in. Then, the user will be directed to this detection menu. The users can choose one of the available buttons to answer the question and continue to the next question by clicking the Next button. The systesm will accept the chosen option by users. Then, the system will match the users' option with the score that has been stored at the database and save the calculated score until the users finish all the questions. The total calculated score will be accumulated and result in the stress categories based on Holmes-Rahe Readjustment Rating Scale.

Figure 7 is the result page. In this page, the user can get their stress level based on their answer before. by Holmes-Rahe Readjustment Rating Scale has categorized the total score. It gathers all answer scores and shows the result in this page.

The users also have a reminder menu after they get the test result. They can request the reminder to their email or not by clicking the button "Remind me to take another test please!!". If they choose to get reminder by clicking the reminder button, the reminder will be sent to the system for the admin. Then, the admin will send the reminder to do another test in three months from the first test time. The reminder will send to the registered email of the users. The purpose of being given a reminder to do the test is that the users can find out whether they are still stressed or not. If the users are still detected to be stress, they can improve their social lifestyle or visit psychology to get the right treatment or solution to solve their problem. By doing the psychological examination or consulting a psychologist, it can have a good impact on the development of one's psychology (Meyer et al., 2001).

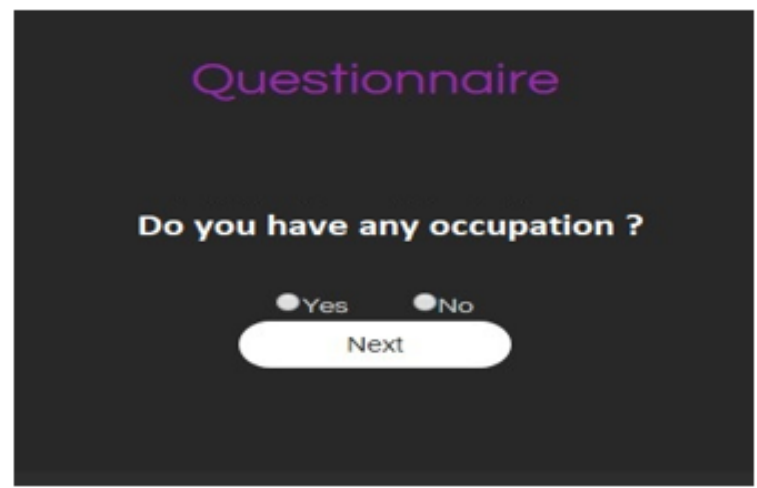

Figure 6 Questionnaire Page 


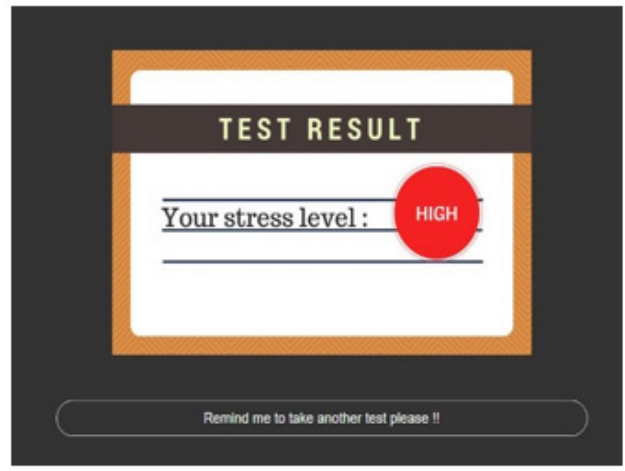

Figure 7 Result Page

The black box testing is done by demonstrating the system and giving a change to all the participants to test this application. The participants are 65 active students at Krida Wacana Christian University. After the users test this application, the researchers distribute the questionnaire. The questionnaire contains four assessed variables. The result of the questionnaire is shown in Figure 8. Based on the result in Figure 8, it can be concluded that the interface and overall of the system have a good review from the users.

Beside the assessed variables, there are some impression and suggestion from the respondent about the system. First, the design is good enough, but it needs more colors. Second, the system is interesting and nice because it can provide a solution. Third, the system is helpful and useful for users to detect stress. Fourth, the questions are too many. To solve it, the researcher should show a few questions on a single page.
The white box testing is done by the developer to measure whether the system works properly or not. The result of this testing method is in Table 2. It shows three testing processes. First, it is the registration process. The test is successful if the registration data by the users is inputted in the database. Second, it is the login process. This testing process is a success if the validation process between the data that inputted by the user and the store data in the database is matched.

Moreover, the other indicator is that the users are directed to the testing page at this system. The last testing process is detecting the stress. The successful indicator is when the system can give the result after the users answer all the questions. Based on all the testing process to this system, it is concluded that all white box testing to this stress detection application is successful, the variables from white box testing are shown in Table 2 .

Table 2 The Variables of White Box Testing

\begin{tabular}{llll}
\hline \multicolumn{1}{c}{ Variable } & \multicolumn{1}{c}{$\begin{array}{c}\text { Testing } \\
\text { Description }\end{array}$} & Expected Result & Conclusion \\
\hline Registration & $\begin{array}{l}\text { Registration data } \\
\text { is inputted to the } \\
\text { database } \\
\text { Login }\end{array}$ & $\begin{array}{l}\text { Registration data } \\
\text { is inputted to the } \\
\text { database }\end{array}$ & Success \\
& $\begin{array}{l}\text { process is } \\
\text { successful } \\
\text { Give the result }\end{array}$ & $\begin{array}{l}\text { The validation } \\
\text { process is } \\
\text { successful }\end{array}$ & Success \\
betect Stress & $\begin{array}{l}\text { Give the result } \\
\text { based on the }\end{array}$ & Success \\
& score & score & \\
\hline
\end{tabular}
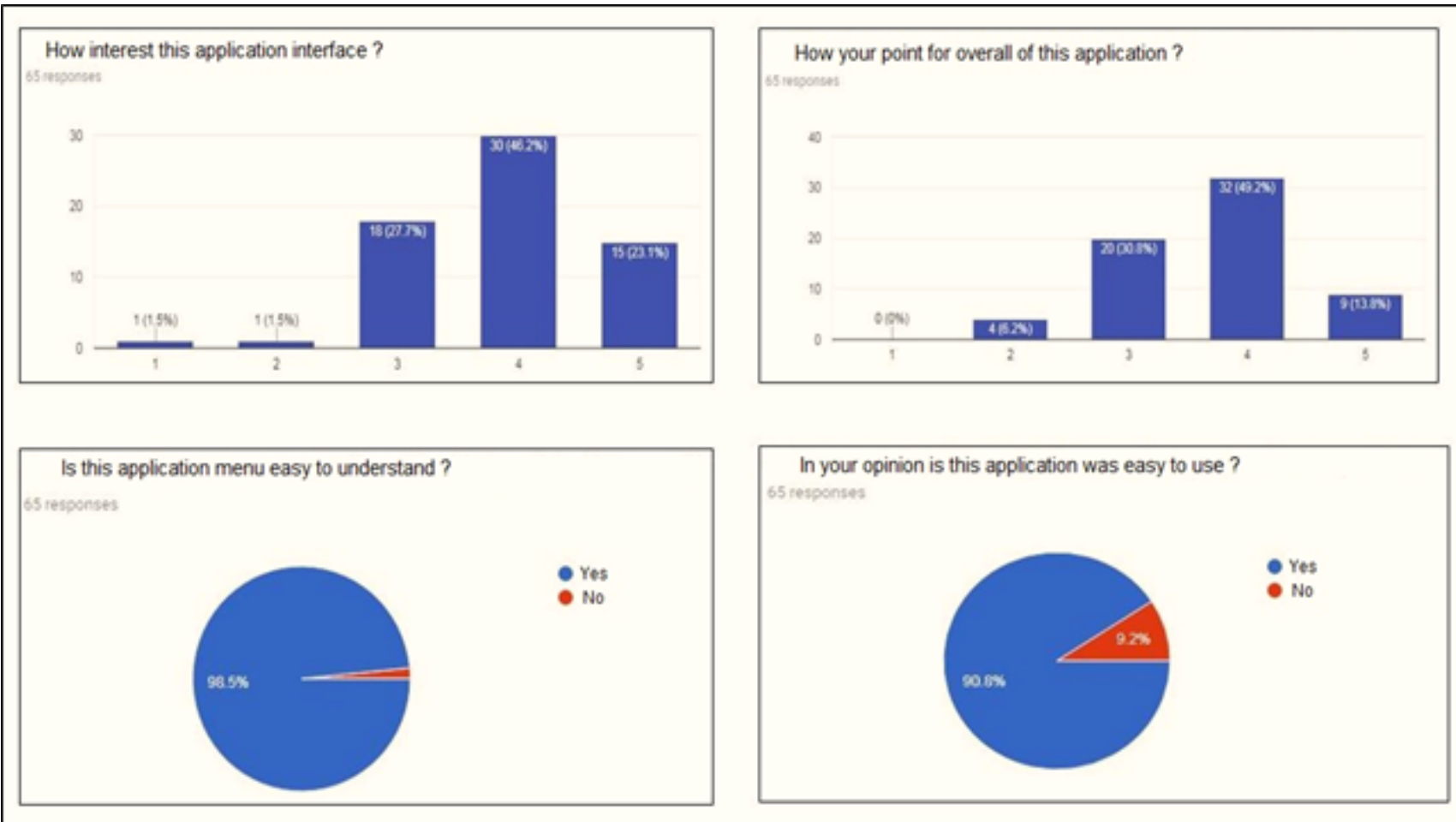

Figure 8 The Result of Black Box Testing 
The success rate of this system can be seen from the total score obtained by the users in the first test compared to the next test. The comparison result can be seen in Table 3 . The lower score shows the success of this system. From the data in Table 3, the system reduces users' stress successfully.

Table 3 Test Results

\begin{tabular}{ccl}
\hline Test 1 & Test 2 & Conclusion \\
\hline 205 & 175 & Lower score \\
260 & 200 & Lower score \\
156 & 54 & Lower score \\
235 & 118 & Lower score \\
187 & 96 & Lower score \\
251 & 201 & Lower score \\
302 & 250 & Lower score \\
281 & 210 & Lower score \\
177 & 116 & Lower score \\
289 & 135 & Lower score \\
\hline
\end{tabular}

The result shows that the implementation of information technology in form of website can be used for college student to detect their stress level. By combining the Holmes-Rahe Readjustment Rating Scale in the website, user can get the reliable stress detection result in convenience and easy ways. This result is accordance with Felsten (2004), Billings et al. (2008), Sevani and Silvia (2015), Oguntimilehin, Abiola, and Adeyemo (2015), and Allexandre et al. (2016).

\section{CONCLUSIONS}

The expert system to detect stress on college student using Holmes-Rahe Rating Scale can be used to detect the student's stress condition to avoid the negative impact of stress early. Moreover, the system also gives some solutions to cope with stress. The system can be accessed through the website. Thus, it is easy and simple to be accessed by the student.

The reminder feature in the system also provides continuous monitoring in the college student stress. With the continuous monitoring, the student stress can be solved before it causes many negative impacts. From the continuous monitoring result, it can be seen that the webbased expert system decreases the users' stress. It is shown from the lower score from the users' test.

Limitation from this system is the right answer from the users. It is an important factor for the system to provide a detection result because this system gives a result based on users' answer to the questionnaire. For the future development of this system, it is expected to add forum or group or chatting discussion that enables the user to communicate directly to a psychologist for consultation. It is also better to add facility to arrange appointment if the user needs to meet the psychologist.

\section{REFERENCES}

Allexandre, D., Bernstein, A. M., Walker, E., Hunter, J., Roizen, M. F., \& Morledge, T. J. (2016). A webbased mindfulness stress management program in a corporate call center: A randomized clinical trial to evaluate the added benefit of onsite group support. Journal of Occupational and Environmental Medicine, 58(3), 254-264. https://doi.org/10.1097/ JOM.0000000000000680

Billings, D. W., Cook, R. F., Hendrickson, A., \& Dove, D. C. (2008). A web-based approach to managing stress and mood disorders in the workforce. Journal of Occupational and Environmental Medicine, 50(8), 960-968. https://doi.org/10.1097/ JOM.0b013e31816c435b

Chakraborty, A. K., Ghorai, A. K., De, R. K., Chakraborty, S., Jha, S. K., Mitra, S., \& Goswami, K. K. (2013). Expert system for integrated stress management in Jute (Corchorus olitorius L. and C. capsularis L.). International Journal of Bio-Resource and Stress Management, 4(2), 192-200.

Felsten, G. (2004). Stress reactivity and vulnerability to depressed mood in college students. Personality and Individual Differences, 36(4), 789-800. https://doi. org/10.1016/S0191-8869(03)00152-1

Gaol, N. T. L. (2016). Teori stres: Stimulus, respons, dan transaksional. Buletin Psikologi, 24(1), 1-11.

Haidar, S. A., de Vries, N. K., Karavetian, M., \& El-Rassi, R. (2018). Stress, anxiety, and weight gain among university and college students: A systematic review. Journal of the Academy of Nutrition and Dietetics, 118(2), 261-274. https://doi.org/10.1016/j. jand.2017.10.015

Meyer, G. J., Finn, S. E., Eyde, L. D., Kay, G. G., Moreland, K. L., Dies, R. R., ... \& Reed, G. M. (2001). Psychological testing and psychological assessment: A review of evidence and issues. American Psychologist, 56(2), 128-165. https://doi. org/10.1037/0003-066X.56.2.128

Oguntimilehin, A., Abiola, O. B., \& Adeyemo, O. A. (2015). A clinical decision support system for managing stress. Journal of Emerging Trends in Computing and Information Sciences, 6(8), 436-442.

Sevani, N., \& Silvia, S. (2015). Web deteksi gangguan kecemasan dan depresi. ULTIMATICS, 7(1), 20-26.

Silitonga, D. V., \& Budiharto, W. (2015). An expert system of measurement of individual knowledge for teeth treatment. International Journal of Software Engineering and Its Applications, 9(4), 11-18.

Subawa, I. G. B., Wirawan, I. M. A., \& Sunarya, I. M. G. (2015). Pengembangan sistem pendukung keputusan pemilihan pegawai terbaik menggunakan metode Simple Additive Weighting (SAW) di PT Tirta Jaya Abadi Singaraja. KARMAPATI (Kumpulan Artikel Mahasiswa Pendidikan Teknik Informatika), 4(5), 24-33. 